\title{
Research on Collaborative Innovation of Intelligent Connected Vehicles Industry Based on Test Field: Embedded Case Study from the Perspective of Open Innovation
}

\author{
Fei Zhou *(D), Yingqi Liu and Ruijun Chen
}

Citation: Zhou, F.; Liu, Y.; Chen, R. Research on Collaborative Innovation of Intelligent Connected Vehicles Industry Based on Test Field: Embedded Case Study from the Perspective of Open Innovation. Sustainability 2021, 13, 5880 . https://doi.org/10.3390/su13115880

Academic Editor: Mouloud Denai

Received: 16 April 2021

Accepted: 18 May 2021

Published: 24 May 2021

Publisher's Note: MDPI stays neutral with regard to jurisdictional claims in published maps and institutional affiliations.

Copyright: (c) 2021 by the authors. Licensee MDPI, Basel, Switzerland. This article is an open access article distributed under the terms and conditions of the Creative Commons Attribution (CC BY) license (https:// creativecommons.org/licenses/by/ $4.0 /)$.
School of Economics and Management, Beijing Jiaotong University, Beijing 100044, China;

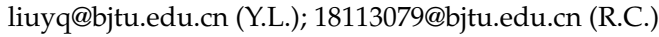

* Correspondence: 19113079@bjtu.edu.cn

\begin{abstract}
Intelligent Connected Vehicles (ICV) are reshaping the pattern of traditional automobile industry, and they have gradually become the strategic direction of more and more countries. The test field and demonstration zones, as important bridges linking the technology side and market side of the ICV, are crucial in the development of its technology and industry. At the same time, the integrated construction of the test field and demonstration zones also provides a platform for collaborative innovation in the industry. In this paper, the test field and demonstration zones of the ICV industry in Beijing are selected as the case study object, and the grounded theory research method is used for reference. Based on the logic of "motivation-behavior-result", the story line of collaborative innovation of ICV industry that is based on the test field is explored. Furthermore, open innovation is incorporated to analyze and optimize the industrial collaborative innovation mechanism that is based on the test field. On this basis, the paper discusses two collaborative innovation paths of the ICV industry based on the test field: the path that is led by the core enterprises in the test field and the path led by the test field. Finally, from the perspective of the government and management departments, several suggestions are put forward for promoting the collaborative innovation of the ICV industry based on the test field, in order to provide reference for the construction and operation of the domestic ICV test field and demonstration zones and the collaborative innovation development of the ICV industry.
\end{abstract}

Keywords: Intelligent Connected Vehicles; test field; collaborative innovation; open innovation

\section{Introduction}

Intelligent Connected Vehicles (also known as Intelligent Vehicles, Autonomous Vehicles, etc.) refer to a new generation of vehicles that are equipped with advanced sensors and other devices, using artificial intelligence and other new technologies, with autonomous driving functions, and gradually becoming intelligent mobile space and application terminals. Iit has gradually become a key development direction of the automobile industry because of its characteristics of informationization, intelligence, networking, and platform, reshaping the pattern of the traditional automobile industry and being an important carrier of many new industries. As a result, ICV are becoming a strategic direction and a must for the future layout of automotive industry in more and more countries, and all countries are increasing their layout to take the first-mover advantage in the new round of automotive industry changes.

Being driven by emerging technologies, such as 5G, AI, big data, IoT, cloud computing, and the support of governments at all levels, the ICV industry is developing rapidly. According to statistics, the global penetration rate of Telematics is about $20 \%$ in 2020 , and that of China is $24 \%$. It is expected to increase to $65 \%$ and $77 \%$, respectively, in 2025 , corresponding to the market space of 1992 billion yuan and 955 billion yuan, respectively. By 2040, the global sales volume of AVs will exceed 30 million [1]. In terms of market size, 
from 2016 to 2019, the market size of ICVs in China has increased from 49 billion yuan to 122.6 billion yuan, with a compound growth rate of $35.8 \%$. By 2021, the market size will further grow to 235.8 billion yuan [2]. At the same time, the sales volume of L2 intelligent connected passenger cars in China will reach 3.032 million in 2020, accounting for 15\% of the total domestic passenger cars, with more than 200 models [3]. The importance of ICV in China's auto market has become more prominent.

Along with the rapid progress of intelligent network technologies and industries, China has realized the landing application in some scenarios and demonstration operation in a specific scope, such as unmanned truck port transportation, unmanned taxi, unmanned cleaning, etc. For example, since April 2020, Baidu has successively opened self-driving cab trial services to the public in Changsha, Beijing, Cangzhou, and Guangzhou; and, DiDi opened self-driving online taxi services in Shanghai in June 2020. However, the industry as a whole is still in the exploration period of transition from technology research and testing to marketization. As an emerging industry, it needs support from various aspects, such as technological innovation, policy planning, laws and regulations, etc. In the field of ICV industry, the support from the test field and demonstration zones is more special. As an indispensable part of the transition from the technical side to the market side, the demand for ICV test field has been gradually increasing along with the development of the industry and, thus, the construction of the test field and demonstration zones in various regions and types has been in full swing in recent years.

Autonomous driving is divided into six levels from L0-L5, according to the classification standards of the Society of Automotive Engineers (SAE). At present, L2 level technology is relatively mature, and it has the conditions for mass production and commercialization. Most autonomous driving companies are in the transition stage of commercialization from L2 to L3 level, and some companies have L3 level or higher autonomous driving technology and are exploring commercialization pilot in specific scenarios. Under Chinese regulations, self-driving vehicles must meet certain road testing standards before entering formal demonstration operations. "ICV Road Testing and Demonstration Application Management Specifications (for Trial Implementation)" (draft for comment) clearly states that "the initial application or increase the configuration of the same demonstration application vehicle, should be in automatic driving mode in the proposed application of the demonstration of road and area over a total of not less than $240 \mathrm{~h}$ or $1000 \mathrm{~km}$ of road testing". Thus, ICV test field and demonstration zones are an indispensable link in the technological innovation and commercialization of autonomous driving applications. From the perspective of industry, the test field can also meet the needs of autonomous driving, from technology development to productization and marketization, and point the way for industrial innovation and business model innovation. Because of its function of linking the technical and application sides, it is highly valued by governments, which have introduced various policies and bills to regulate the management of road testing.

The ICV test field can be divided into a virtual simulation test platform and a closed test field, according to the testing means. Among them, virtual simulation test platforms are mainly independently developed by enterprises with technological advantages, most of which are Internet or high-tech enterprises, such as Tencent's TAD Sim system and ICV simulation laboratory, 51VR's 51Sim-One simulation platform, and Waymo's Carcraft platform. Because of its relatively low cost, high security, repeatable testing, high testing efficiency, and flexible scenario configuration [4], it can be used as a supplement to the closed test field. However, whether from the perspective of government regulations or practical applications, the construction of closed test field is a top priority. There are more than 50 autonomous driving test fields and demonstration zones open or under construction in China, including eight national test fields that are supported by the Ministry of Industry and Information Technology, such as the Intelligent Vehicle and Intelligent Transportation (Beijing-Hebei) Demonstration Zone, the National ICV (Shanghai) Demonstration Zone, and Chongqing i-VISTA. Closed road testing is a necessary link before the demonstration and application of self-driving vehicles, as stipulated by the policy, and also a prerequisite 
for mass production and marketization. It not only plays an important role as a bridge for industrial landing, but it also serves as a platform for industrial collaborative innovation. Because many test fields in China adopt the method of integrated construction of test fields and demonstration areas, they usually gather multiple types of innovation subjects, such as government, industry, university, research, and application, and, thus, have the conditions to become independent industrial innovation alliances.

Collaborative innovation is one of the important paths for the development of the ICV industry. In February 2020, the National Development and Reform Commission and another 11 departments issued the "Intelligent Vehicle Innovation and Development Strategy", which clarifies the basic principles for the development of the intelligent vehicles industry, emphasizing collaborative promotion, innovation-driven, cross-border integration, and open cooperation. In October 2020, the General Office of the State Council issued the "New Energy Vehicle Industry Development Plan (2021-2035)", which also proposed the implementation of intelligent network technology innovation projects and support for cross-border collaboration among enterprises. Openness, cross-border, synergy, and innovation have become the key words for the development of China's ICV industry. On the other hand, ICV have cross-industry and interdisciplinary crossover characteristics, integrating multiple industries, such as automobile, communication, Internet, and big data, and involving multiple technical fields, such as perception, decision-making, communication, and control. This determines that its development is difficult to achieve by a single enterprise or even a single industry, and it requires cross-enterprise and cross-industry synergy. In terms of collaborative innovation, China has set up innovation platforms, such as the National ICV Innovation Center, the China ICV Industry Innovation Alliance, and the Zhongguancun Intelligent Transportation Industry Alliance on the basis of the test field, and other industrial alliances that are oriented to common technologies and industry chain collaborative innovation. With the goal of being innovation-driven, they accelerate the pace of technological innovation and industrial innovation by gathering innovation resources, fostering innovation subjects, and forming cross-industry and cross-enterprise synergy mechanisms. In particular, the unique two-in-one construction mode of our test field and demonstration zone gives it the natural advantage of synergistic development. At present, although some test fields have made full use of this advantage to establish industrial consortia or industrial alliances to realize collaborative innovation, the test fields in China are still in the early stage of construction and operation. With infrastructure construction and vehicle testing as the primary focus, the number and types of innovative subjects in the test field are few, and the inter-enterprise cooperation and synergistic effect of industry have not been fully exerted. Most of the test field are developed independently of each other, and there are large barriers to data interoperability and information and resource circulation, which do not form a synergy and hamper the cultivation of industrial innovation ecology.

Based on this, this paper takes the innovation subjects in the closed test field (including the demonstration zones) as the main research objects, and it explores the collaborative innovation methods, mechanisms, and paths among the innovation subjects in the test field of China's ICV through the method of case study, with a view to reducing the phenomenon of industrial information silos in the test field. It provides reference for forming a collaborative innovation mechanism of the ICV industry with the test field as the core, building an industrial ecosystem with the test field as the platform, and accelerating industrial innovation development.

\section{Literature Review and Theoretical Basis}

ICV are reshaping the structure of the automotive industry, but as an emerging industry, they have not yet formed a complete industrial system [5], and they are also facing numerous problems in technology and industrial development [6], which need to be solved by technological innovation and industrial innovation. Additionally, because of the complexity and interdisciplinarity of the ICV technology, it is difficult to rely on the resources of 
a single enterprise to solve all industrial problems. Facing the requirements of this emerging industry for technological innovation, scholars put forward the concept of open innovation that breaks the boundaries of enterprises, unites external organizations, and makes full use of, and integrates, the technology, knowledge, and other resources outside the enterprise to achieve internal innovation $[7,8]$. On the one hand, as an emerging industry, most of the current ICV enterprises are in the initial and exploratory stage, lacking experience and knowledge accumulation. Open innovation as an effective innovation approach can effectively improve the enthusiasm of enterprise innovation, especially for emerging industries [9]. Unlike closed innovation, which focuses on the internal approach of a single firm, open innovation increases the external access to innovation resources of the firm and improves the holistic nature of $R \& D$ and innovation based on a wide range of knowledge and technology. Moreover, open innovation emphasizes the use of external resources throughout the process from idea generation to product commercialization [10], and it has become an important strategic paradigm to support continuous innovation within an organization [11], which is applicable to the current transformation phase of ICV from R\&D to commercialization. Open innovation can be used to fully integrate internal and external resources, enrich and supplement the existing knowledge structure and system, improve innovation and problem-solving capabilities, and then promote the development of new products and businesses in the ICV industry and their commercialization [12]. On the other hand, the combination of open innovation and collaborative innovation can be applied to the collaboration and sustainable development among industrial organizations, and the construction of open collaborative innovation system can promote the establishment of an industrial ecosystem and the cooperation between industry, academia, and research [13]. In addition to acquiring external technical knowledge, open innovation is more important for acquiring inter-organizational knowledge synergy. The implementation process of open innovation is the process of the synergy of internal and external resources as well as the technologies of enterprises [14]. Inward and outward open innovation and the synergy between them have a significant contribution to innovation performance [15]. Many scholars have explored the characteristics, motivations, processes, collaborative innovation models, and paths that are presented by inter-firm collaboration under the perspective of open innovation $[16,17]$. Therefore, open innovation can be effectively combined with collaborative innovation in the ICV industry.

For the sources of external resources in open innovation, Laursen et al. (2006) grouped them into four categories with a total of 16 sources, namely: market elements, such as suppliers, customers, and competitors; institutional elements, such as universities, government, and other public sectors; professional standard elements, such as technical standards and environmental standards; and, other elements, such as trade associations, conferences, and exhibitions [18]. This almost covers the main sources of external motivation for firms to innovate. In addition, scientific and technological intermediaries, research institutions, and other factors are often considered [19,20]. Unlike foreign countries, the external power sources of enterprise open innovation in the Chinese context generally do not consider elements, such as conferences and exhibitions, but the main sources also include customers, suppliers, competitors, universities and research institutes, science and technology intermediaries, and government [21,22].

The agglomeration of various subjects makes Chinese test fields naturally equipped with the platform conditions for collaborative innovation among the subjects. What kind of open innovation paths and methods can each subject of the test field use to realize the full utilization of platform resources and promote collaborative innovation in the ICV industry has become the focus of research. Scholars have also discussed this issue in numerous ways. Yufen Chen and Jin Chen (2009) believe that common open innovation approaches include cooperation with customers and suppliers, setting up research alliances, promoting cooperation among industries, universities, and research institutes, establishing joint ventures, and purchasing patents and technology usage rights [23]. Yin Yuanyuan (2019) considers open innovation models in the form of open innovation platforms, co- 
operative R\&D, industry-university-research cooperation, and RJVs [24]. Xie X (2020) identifies six models for firms to participate in open innovation: "inter-firm cooperation", "firm-university-research institution cooperation", "business-intermediary cooperation", "business-user cooperation", "divestiture", and "technology transfer" [25].

The current academic research on test field is mainly divided into the following categories: first, research on the test technology and test scenarios of autonomous driving vehicles [26,27]. Second, research and evaluation on the current situation, characteristics, and future prospects of test field construction and operation at home and abroad [28,29]. Third, research on the current situation and future development ideas of domestic and international road-testing policies and regulations [30-32], of which safety regulatory system and administrative regulations are more concerned in the current research [33,34]. Fourth is the research that is related to the virtual testing platform for autonomous driving $[35,36]$. Fifth is the public's awareness and willingness to accept autonomous driving road tests [37]. Along with the rapid development of the ICV industry, the importance of the test field in technological innovation and industrialization has become increasingly prominent.

At present, the research in academia mainly focuses on the road-testing policy and the test field itself. The research on the industry itself is also mostly focused on technology, the current state of industrial development, policies, and regulations, etc. The research on the collaborative innovation of the industry that is based on the test field is relatively scarce. On the basis of summarizing the main subjects gathered in the test field of ICV, this paper identifies the sources of innovation subjects of open innovation in the test field by combining the research results of scholars. Subsequently, it explores the collaborative innovation approach of the ICV industry based on the test field through a case study approach, and it improves the collaborative innovation mechanism and path from the perspective of open innovation.

\section{Research Design and Case Study Analysis}

\subsection{Research Design}

\subsubsection{Research Methodology}

Although there are various research methods for industrial collaborative innovation, common ones include case studies, network analysis, empirical analysis, and so on. However, the ICV industry is still in its infancy, and it has not yet formed a market for mass production at the present stage. The test field and demonstration zones are mostly at the early stage of construction and operation, with few mature business models and a lack of industry data support. Therefore, it is difficult to conduct research through quantitative methods. Consequently, the current research on the ICV industry is mostly based on qualitative research methods, such as case studies and literature studies [32,38]. In addition, most of the current academic discussions on the test field and demonstration zones of ICV are focused on the road test policy and how to plan and construct them, but there is a lack of theoretical support for the test field as a platform for industrial cooperation to facilitate industrial innovation. In addition, this study aims to discuss the impact of the test field of ICV as a platform on industrial collaborative and innovation, focusing on answering the questions of "Why" and "How". Therefore, it is suitable to construct and develop theories through case studies to explore the industrial development logic and rules behind the phenomenon [39]. Specifically, the embedded case study approach is used to select multiple test fields in the same system, which is, Beijing, as sub-cases to reveal the patterns.

\subsubsection{Case Selection}

In this paper, we select cases by theoretical sampling [40], because the ICV test field and demonstration zones in Beijing started early and gathered relatively more test field. The operation is relatively mature, the industry has begun to take shape, and a collaborative industrial innovation trend that is based on test field and demonstration zones has initially been formed. In addition, Beijing has a rich collection of innovative elements, such as Tsinghua, Beijing Institute of Technology, Beijing University of Aeronautics and 
Astronautics, National University of Defense Technology, and other major universities and their high-end talents who are at the forefront of the R\&D of ICV technology. There are also research institutions, such as The National ICV Innovation Center, the National Automobile (Beijing) ICV Research Institute, Tsinghua University Institute of Automotive Industry and Technology Strategy, and so on. At the same time, Beijing is a gathering place for leading companies, such as Baidu, JD.com, and Meituan, as well as self-driving unicorns, such as IDRIVERPLUS, Pony.ai, and TuSimple, with rich resources for collaborative innovation of various subjects. Therefore, the test field in the Beijing area are selected as the research objects, mainly including the National Intelligent Vehicle and Intelligent Transportation (Beijing-Hebei) Demonstration Area Yizhuang Base (Beijing Economic Development Zone), Haidian Base (within Zhongguancun Science City), Shunyi ICV Innovation and Ecology Demonstration Zone, Beijing ICV Demonstration and Operation Zone (Shougang Park), and Fangshan 5G Autonomous Driving Demonstration Zone.

\subsubsection{Data Collection}

In this paper, the data were collected from multiple sources, including both primary and secondary sources. The primary data are mainly from field research and observation, structured interviews, and open-ended interviews. The secondary data include the policies and regulations that are related to the ICV issued by Beijing; the relevant policies issued by the management committees of the parks; the reports related to the ICV industry and road testing issued by Beijing; the public speeches of relevant leaders, park leaders, entrepreneurs, etc.; and, the relevant reports on official websites, official microblogs, official media, and other public information on and offline. A total of about 362,000 words of textual information was compiled (Table 1), which was used to meet the requirements of triangulation validation [40] and improve the reliability and validity of the case study.

Table 1. Source of case study data.

\begin{tabular}{|c|c|c|}
\hline Test Field/Demonstration Zone & First-Hand Information & Second-Hand Information \\
\hline $\begin{array}{l}\text { National Intelligent Vehicle and Intelligent } \\
\text { Transportation (Beijing-Hebei) Demonstration } \\
\text { Zone Yizhuang Base and Haidian Base }\end{array}$ & $\begin{array}{l}\text { Three semi-structured interviews } \\
\text { (approximately 35,000 words). } \\
\text { Field observation records (approximately } \\
0.7 \text { million words). }\end{array}$ & \multirow{4}{*}{$\begin{array}{l}\text { Various media coverage (approximately } \\
110,000 \text { words). } \\
\text { Relevant policy documents of Beijing and the } \\
\text { park ( } 6 \text { copies, about } 70,000 \text { words). } \\
\text { Reports related to the ICV industry and road } \\
\text { testing in Beijing ( } 4 \text { copies, about } \\
65,000 \text { words). }\end{array}$} \\
\hline $\begin{array}{l}\text { Shunyi ICV Innovation Ecological } \\
\text { Demonstration Zone }\end{array}$ & $\begin{array}{l}\text { Two semi-structured interviews } \\
\text { (approximately 27,000 words). } \\
\text { Field observation records (approximately } \\
0.5 \text { million words). }\end{array}$ & \\
\hline $\begin{array}{l}\text { Beijing ICV Demonstration Operation Area } \\
\text { (Shougang Park) }\end{array}$ & $\begin{array}{c}3 \text { semi-structured interviews ( } 32,000 \text { words). } \\
\text { Field observation records (approximately } \\
0.5 \text { million words). }\end{array}$ & \\
\hline $\begin{array}{l}\text { Fangshan 5G Autonomous Driving } \\
\text { Demonstration Zone }\end{array}$ & $\begin{array}{l}\text { Field observation records (approximately } \\
0.6 \text { million words). }\end{array}$ & \\
\hline
\end{tabular}

\subsection{Data Processing and Case Analysis}

In this paper, we use the coding method in grounded research for reference. We coded the collected data step-by-step, summarized the concepts, and then classified them, and finally formed theoretical interpretations [41].

\subsubsection{Open Coding}

Firstly, the collected textual materials were sorted out line-by-line and sentence-bysentence, and the original statements that were related to the collaborative innovation of the industry with the ICV test field and demonstration zone as the platform were screened out, labeled (a), and conceptualized (A) were coded. Subsequently, the concepts with high correlation were further summarized and refined, and the logically related concepts were aggregated into the same category and named (AA). A total of 127 concepts were refined through the collation of the data and then finally grouped into 32 categories (Table 2). 
Table 2. Example of open coding.

\begin{tabular}{|c|c|c|}
\hline \multirow{2}{*}{ Typical Information } & \multicolumn{2}{|c|}{ Open Coding } \\
\hline & Conceptualization & Categorization \\
\hline $\begin{array}{l}\text { ICV have the characteristics of great intersection of disciplines and great integration of } \\
\text { multiple industries (a1) ..... Integration and innovation and open cooperation are the } \\
\text { characteristics of the times for the development of ICV (a3)..... }\end{array}$ & $\begin{array}{l}\text { A1 Interdisciplinary } \\
\ldots \ldots \\
\text { A3 Industrial } \\
\text { characteristics of } \\
\text { The Times }\end{array}$ & $\begin{array}{l}\text { AA1 Characteristics } \\
\text { of industrial } \\
\text { development }\end{array}$ \\
\hline$\ldots \ldots$ & $\ldots \ldots$ & $\ldots \ldots$ \\
\hline $\begin{array}{l}\text { To achieve faster scenario landing for autonomous driving, it also needs more ecological } \\
\text { power, especially the participation of Internet technology companies (a18). }\end{array}$ & A18 Scene landing & $\begin{array}{l}\text { AA7 Drives scenarios } \\
\text { to the ground }\end{array}$ \\
\hline $\begin{array}{l}\text { Actively unblocking the channel for the docking of innovation resources and the } \\
\text { implementation of achievements projects in the "Three Cities" (A19) ..... We will hold } \\
\text { regular seminars and forums on autonomous driving-related applications (a22). }\end{array}$ & $\begin{array}{l}\text { A19, A20 Open } \\
\text { communication channels } \\
\text { A21, A22 break the } \\
\text { communication barrier }\end{array}$ & $\begin{array}{l}\text { AA8 Break barriers } \\
\text { and open channels }\end{array}$ \\
\hline$\ldots \ldots$ & $\ldots \ldots$ & $\ldots \ldots$ \\
\hline $\begin{array}{l}\text { Establish and improve the linkage development mechanism of the three regions, accelerate } \\
\text { the integrated development of Taihu and Majuqiao areas and the core area of the } \\
\text { development zone (a105) ....... Accelerate the market connection and project cooperation } \\
\text { with key regions in Beijing-Tianjin-Hebei, and build a cross-regional, multi-echelon } \\
\text { industrial development layout with enterprises as the main body ....... (a111). }\end{array}$ & $\begin{array}{c}\text { A105, A106 Joint } \\
\text { development of the park } \\
\ldots \ldots \text {.... } \\
\text { A109, A110, A111 } \\
\text { Collaborate layout } \\
\text { across regions }\end{array}$ & $\begin{array}{l}\text { AA24 } \\
\text { Cross-district linkage }\end{array}$ \\
\hline $\begin{array}{c}\text {...... For Audi its a favourable position, will greatly accelerate the progress of the } \\
\text { enterprise's R\&D innovation (a112) ... ... The development of the domestic ICV industry is } \\
\text { still facing numerous key technical bottlenecks. The cooperation among various subjects } \\
\text { realizes complementary advantages and speeds up the breakthrough of technical } \\
\text { bottlenecks. (a113) }\end{array}$ & $\begin{array}{l}\text { A112 Accelerate } \\
\text { enterprise R\&D } \\
\text { innovation } \\
\text { A113 Key technology } \\
\text { breakthrough and } \\
\text { upgrade }\end{array}$ & $\begin{array}{l}\text { AA25 Improving the } \\
\text { technological } \\
\text { competitiveness of } \\
\text { enterprises }\end{array}$ \\
\hline$\ldots \ldots$ & $\ldots \ldots$ & $\ldots \ldots$ \\
\hline $\begin{array}{c}\text {...... It seems that the adsorption effect of the Smart Town demonstration project has } \\
\text { already appeared, and more and more innovative enterprises and projects are gathering } \\
\text { here (a127). }\end{array}$ & A127 Adsorption effect & $\begin{array}{l}\text { AA32 Enhances the } \\
\text { adsorption effect }\end{array}$ \\
\hline
\end{tabular}

\subsubsection{Spindle Type Coding}

After the open coding, the above initial categories are deeply excavated and found to establish the logical relationships among them. The 32 initial categories were grouped into 12 main categories (Table 3), which were refined according to the motives, behaviors, and results of collaborative innovation based on the test field. "Motivation" refers to the reasons and conditions for the test field and its enterprises to carry out cooperative exchanges and collaborative innovation. "Behavior" refers to the ways and strategies of carrying out collaborative innovation. "result" refers to the effect of collaborative innovation.

\subsubsection{Selective Coding}

Selective coding is based on the main axis coding, and the logical relationships between the main categories presented are further summarized and refined [42], and then the core categories are explored. In this study, the core categories are summarized through the universal logic of "Motivation-Behavior-Result", and the different categories are linked around the core categories through hypotheses or relationship diagrams [43], forming a relatively clear "story line". In this process, the information set aside was used to perform a theoretical saturation test to ensure that the existing core categories were saturated, and no new categories or relationships were generated. Consequently, the "story line" of collaborative innovation in the ICV industry based on the test field that is shown below was obtained (Figure 1). 
Table 3. Coding Analysis.

\begin{tabular}{|c|c|c|}
\hline Core Scope & Main Category & Sub-Categories \\
\hline \multirow{3}{*}{ Motivation } & Industry endogenous factors & $\begin{array}{c}\text { Characteristics of industrial development; industrial development needs; } \\
\text { willingness to cooperate }\end{array}$ \\
\hline & Environmental exogenous factors & Top-level support; resource base \\
\hline & Synergistic advantages & Have the advantage of platform; drive the scene to land \\
\hline \multirow{6}{*}{ Behavior } & $\begin{array}{l}\text { Accelerate the gathering of } \\
\text { innovation resources }\end{array}$ & $\begin{array}{l}\text { Break down barriers and open channels; supporting environmental } \\
\text { construction; attracting investment }\end{array}$ \\
\hline & Build an innovative cooperation platform & Establish industry alliances; create platforms \\
\hline & Promoting R\&D cooperation & $\begin{array}{l}\text { Joint construction of research platform; joint technological research; } \\
\text { technology integration }\end{array}$ \\
\hline & Building Industrial Clusters & $\begin{array}{l}\text { Attracting enterprises to move in; promoting industrial clustering; } \\
\text { promoting industrial integration }\end{array}$ \\
\hline & Create an industrial ecosystem & $\begin{array}{l}\text { Develop the whole industry chain; Integration of test and demonstration } \\
\text { application; promote coordination between human, vehicle, road, cloud, } \\
\text { network and city; promote cooperation between government, industry, } \\
\text { academia, research and use }\end{array}$ \\
\hline & Promote cross-district linkage & Cross-district linkage \\
\hline \multirow{3}{*}{ Result } & Business growth & $\begin{array}{l}\text { Improve enterprise technology competitiveness; accelerate } \\
\text { commercial operation }\end{array}$ \\
\hline & Industrial progress & $\begin{array}{l}\text { Data sharing and value-added; promoting industrialization; promoting } \\
\text { industrial technology standardization }\end{array}$ \\
\hline & Socio-economic benefits & $\begin{array}{l}\text { Promote regional economic growth; improve traffic efficiency and safety; } \\
\text { enhance the adsorption effect }\end{array}$ \\
\hline
\end{tabular}

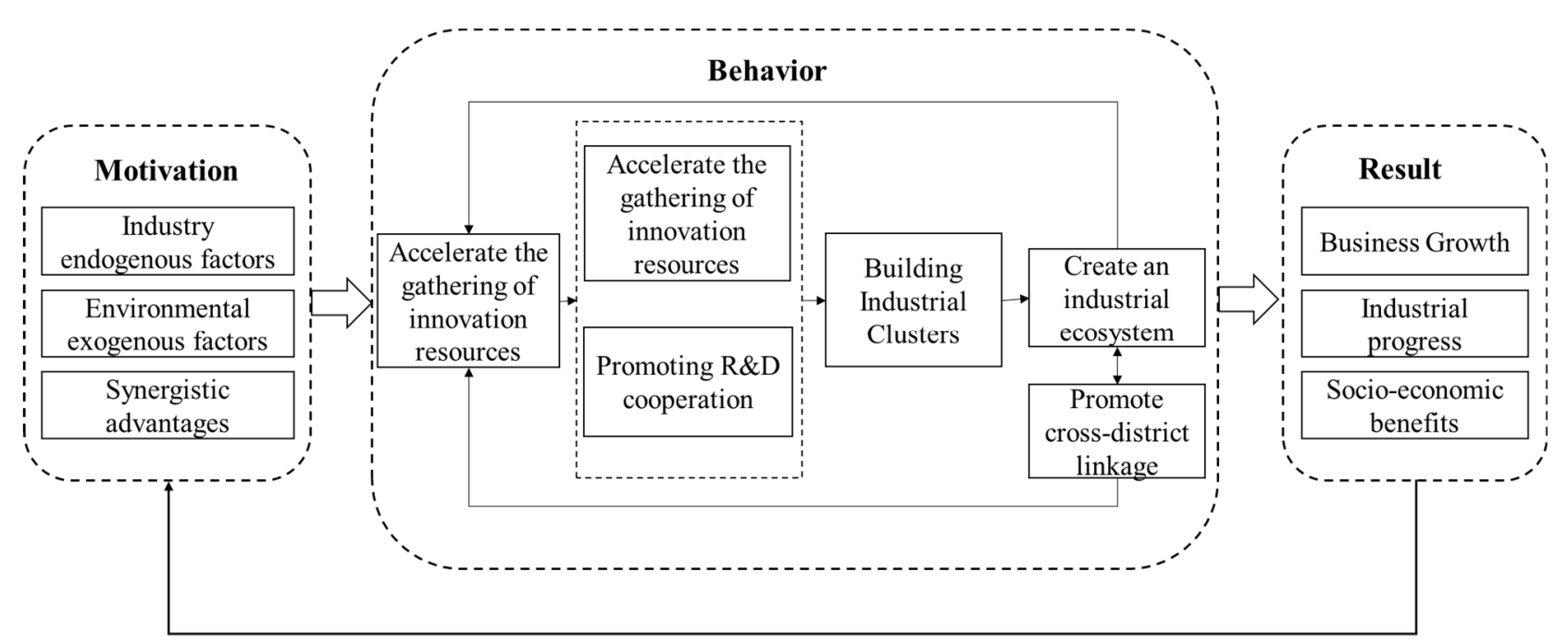

Figure 1. The "story line" of collaborative innovation in the ICV industry based on the test field.

According to the above results, the motivation of collaborative innovation in the ICV industry that is based on the test field mainly includes industrial endogenous factors, environmental exogenous factors, and synergistic advantages. Among them, the endogenous factors of the industry are: first, the ICV industry itself has the characteristics of major interdisciplinary, multi-industry integration, and so on. Second, many key problems in the process of industrial development depend on the synergistic solution among various subjects. Third, some enterprises and test fields have expressed their willingness to cooperate, especially the weaker small and medium-sized enterprises, which are more willing to cooperate. Environmental exogenous factors are mainly the external conditions that support collaborative innovation. The top-level design of the government encourages industrial cooperation, and the test field or demonstration zones are also equipped with the 
conditions for the agglomeration and development of industrial resources and innovation resources. The synergistic advantage means that realizing collaborative innovation in the ICV industry based on the test field can provide a platform for industrial development and promote the landing of scenarios.

Accelerating the gathering of innovation resources, building an innovation cooperation platform, promoting $R \& D$ cooperation, building industrial clusters, creating an industrial ecosystem, and promoting cross-regional linkage are the main ways of promoting industrial collaborative innovation based on the test field. Among them, accelerating the gathering of innovation resources is the foundation. By improving the supporting environment of the test field, opening up channels of exchange and cooperation in various ways, and attracting investment to accelerate the gathering of knowledge, talent, and other innovation resources in education, scientific research, financial investment, and other areas in the region. On this basis, build various innovation cooperation platforms for industrial cooperation, such as industrial regional platforms, infrastructure platforms, market-oriented platforms, enterprise service platforms, and industrial alliance platforms that are led by the government or core enterprises. Encouraging all kinds of subjects to jointly build research platforms, promote R\&D cooperation through technology integration, joint research, and other forms, and promote technological collaborative innovation. Further, attract all kinds of autonomous driving-related enterprises by supporting headquarters enterprises and encouraging foreign investment. Promote industrial clustering by stimulating the cluster effect of leading enterprises, multi-industry integration, etc. Encouraging cross-industry integration, build multi-industry integration towns, etc. to promote the integration of related industries, so as to promote the establishment of ICV industrial clusters. Finally, we will further build a benign integrated ecosystem on the basis of industrial clusters. This includes the development of the whole industry chain of the ICV industry including upstream, midstream, downstream, and extended industries, the integrated and collaborative development of human-vehicle-road-cloud-network-city, the integrated construction of R\&D-test-demonstration application-production, and the construction of the cooperation system of government, industry, academia, research, and application. In the process of these actions, cross-regional linkage can be promoted by strengthening the connection with the other test field, demonstration zones, or related parks, co-built demonstration parks, cross-provincial, and urban industrial synergy layout, etc. to realize the cross-regional flow and allocation of innovation resources, innovation subjects, innovation achievements, etc.

The results of collaborative innovation can be discussed in three aspects: business growth, industrial progress, and improvement of social and economic benefits. In the aspect of business growth, collaborative innovation that is based on the test field will accelerate the speed of enterprise R\&D innovation, especially the technical cooperation among enterprises is important for the breakthrough and upgrading of key technologies, thus enhancing the technological competitiveness of enterprises. The cooperation between industry, academia, research, and application, as well as cooperation among various enterprises, will accelerate the pace of mass production of ICV and speed up the process of commercial operation. In the aspect of industrial progress, coordination and cooperation between the test field testing field linkage can open up the sharing channels of various kinds of data, especially test data, promote the construction of industrial data sharing platform, increase the amount of data, and enhance the value of data, which can use big data better for technology improvement and upgrading, reduce unnecessary testing and demonstration risks, and promote industrial integration. In addition, the test field builds a cooperation platform for all kinds of relevant subjects of ICV, facilitating their joint development of ICV-related technologies and industrial standards, and promoting the standardization of industrial technologies and industrialization on the ground. For example, the Intelligent Vehicle Alliance, together with the leading enterprises in the industry and the test field alliance, released the first domestic road test evaluation standards and group standards for autonomous driving vehicles. Developing several standards 
and specifications, such as technical specifications for autonomous driving pure electric minibuses, technical requirements for autonomous driving simulation test platforms, and technical requirements for test field, to further promote the industrialization of ICV on the ground. Regarding socio-economic benefit enhancement, first, the development of the industry and the increasing growth of output value will promote the growth of the regional economy. Second, the progress and landing of autonomous driving technology is also important for improving the efficiency of traffic and traffic safety. Third, the synergy and agglomeration development of industries in the region will optimize the regional industrial development environment, improve the attractiveness to various innovative enterprises and resources, enhance the adsorption effect of the region, and improve the regional innovation environment and capacity. The excellent results that are brought by collaborative innovation will then become one of the motives for industrial collaborative innovation.

\section{Collaborative Innovation Mechanism and Path of ICV Industry}

The "story line" of "Motivation-Behavior-Result" of collaborative innovation of the ICV industry based on the test field was obtained through the above case coding and analysis of the test field of ICV in Beijing. The open innovation is further incorporated into this "story line" to optimize the collaborative innovation mechanism based on the ICV test field as a platform, and it is extended to most domestic test fields and demonstration zones.

Firstly, the sources of external resources in open innovation in the test fields are clarified. The study provides statistics on the current major players within China's ICV test field (Figure 2). At present, most test fields in China are jointly built by the government and enterprises, and the government takes the lead. According to the statistics, the main members in the existing ICV test field and demonstration zones can be roughly divided into four categories, government, enterprises, universities, and research institutions.

\begin{tabular}{|c|c|c|c|c|}
\hline $\begin{array}{l}\text { Classification of } \\
\text { innovation subjec }\end{array}$ & & erprise & & $\begin{array}{l}\text { Research } \\
\text { institution }\end{array}$ \\
\hline $\begin{array}{c}\text { National Intelligent } \\
\text { Connected Vehicles } \\
\text { (Shanghai) Demonstration } \\
\text { Zone }\end{array}$ & $\begin{array}{l}\text { IMIIT; Shanghai Municipal } \\
\text { ICommission of Economy and } \\
\text { Information Technology; } \\
\text { Iiading District Government } \\
\end{array}$ & $\begin{array}{l}\text { Shanghai International Automobile City, } \\
\text { Changan Automobile, BAIC, SAIC, NIO } \\
\text { GM, Ford, Tesla, Toyota, Bosch, } \\
\text { Continental, Harman, Baidu, Datang } \\
\text { Telecom, Infineon, ZTE, Huawei, China } \\
\text { Mobile, etc }\end{array}$ & $\begin{array}{l}\text { Tsinghua University, Tongji } \\
\text { University, Shanghai Jiaotong } \\
\text { University, Jilin University, etc }\end{array}$ & $\begin{array}{l}\text { CAICT, CATARC, The Third } \\
\text { Research Institute of the } \\
\text { Ministry of Public Security, } \\
\text { CAERI, National Eastern } \\
\text { Tech-Transfer Center, etc }\end{array}$ \\
\hline $\begin{array}{c}\text { Chongqing i-VISTA } \\
\text { intelligent vehicle integrated } \\
\text { system test zone }\end{array}$ & $\begin{array}{l}\text { MIIT、Chongqing } \\
\text { Municipal Government }\end{array}$ & $\begin{array}{l}\text { SAIC GM-Wuling, BAIC New } \\
\text { Energy, BAIC Foton, Honda, JAC, } \\
\text { MSCSoftware, NavInfo, Siemens, } \\
\text { Toyota Investment, etc }\end{array}$ & $\begin{array}{l}\text { Tsinghua, Tongji University, Beijing } \\
\text { University of Aeronautics and } \\
\text { Astronautics, Jilin University, } \\
\text { Hunan University, University of } \\
\text { Leeds, University of Michigan, etc }\end{array}$ & $\begin{array}{l}\text { CAERI, CICV, China } \\
\text { Software Evaluation } \\
\text { Center, etc }\end{array}$ \\
\hline $\begin{array}{c}\text { National Intelligent Vehicle } \\
\text { and Intelligent } \\
\text { Transportation (Beijing- } \\
\text { Hebei) Demonstration Zone }\end{array}$ & $\begin{array}{l}\text { MIIT、 Beijing Municipal } \\
\text { Bureau of Economic and } \\
\text { Information Technology }\end{array}$ & $\begin{array}{l}\text { Toyota, BAIC, } \\
\text { NIO,UISEE,IDRIVEPLUS, NavInfo, } \\
\text { AMAP, Meituan, Baidu, Didi, China } \\
\text { Mobile, Qianfang, Jingdong, etc }\end{array}$ & $\begin{array}{l}\text { Tsinghua, Beijing Jiaotong } \\
\text { University, Beijing University of } \\
\text { Technology, Beijing University of } \\
\text { Aeronautics and Astronautics, } \\
\text { Beijing Wuzi University, etc }\end{array}$ & $\begin{array}{l}\text { CAICT, China Software } \\
\text { Evaluation Center, etc }\end{array}$ \\
\hline $\begin{array}{c}\text { Guangzhou Intelligent } \\
\text { Connected Vehicle and } \\
\text { Intelligent Transportation } \\
\text { Application Demonstration } \\
\text { Zone } \\
\end{array}$ & $\begin{array}{l}\text { MIIT、 Guangdong } \\
\text { Provincial Government, } \\
\text { Guangzhou Municipal } \\
\text { Government }\end{array}$ & $\begin{array}{l}\text { Guangzhou Public Transportation } \\
\text { Group, GAC, Honda, WeRide, Xpeng, } \\
\text { Songhong Intelligence, Frontier, } \\
\text { CETC, Unicom Intelligent Network, } \\
\text { Genvict, Guangzhou FOISON, etc }\end{array}$ & $\begin{array}{l}\text { Sun Yat-sen University, Tongji } \\
\text { Southeast University, South China } \\
\text { University of Technology, Henan } \\
\text { University, Guangzhou University, } \\
\text { South China Normal University, etc }\end{array}$ & $\begin{array}{l}\text { CEPREI, CNEARI, ISCAS, } \\
\text { NAST, etc }\end{array}$ \\
\hline
\end{tabular}

Figure 2. Classification table of the subjects of China's ICV test field/demonstration zones (partial).

The enterprises in the current test field are mainly auto-driving-related and technologybased enterprises, and there are relatively few financial investment institutions and technology service intermediaries. However, as an important supporting resource for science and technology innovation, it plays an important role in the improvement of regional innovation environment, and most of the industrial parks have made the introduction of financial and technology intermediaries one of their important tasks. For example, the 
"Fifteen Measures on Supporting the Innovation-Led Development of ICV Industry in Zhongguancun Science City" proposes strengthening financial capital support by joint investment institutions, etc. When combined with the research results of other scholars, financial investment and science and technology intermediaries should also be made as one of the external sources of open innovation. When the ICV enter the demonstration and operation stage, it will also involve the users as the main body. Therefore, the main power sources of open innovation in the test field are divided into five main categories: government, enterprises, universities and research institutions, financial investment and technology intermediaries, and users. Accelerating the gathering of innovation resources, building innovation platforms, constructing industrial clusters, etc., carry out the process of the selection and cultivation of subjects. On this basis, the open and collaborative innovation of multiple subjects based on the test field is formed.

In the main collaborative innovation system under the perspective of open innovation, the components mainly include four parts: first, the core enterprises of ICV, including automobile manufacturers (traditional automobile manufacturers, new energy vehicles manufacturers, etc.), high-tech enterprises, Internet enterprises, autonomous driving startups, and other enterprises engaged in R\&D and the manufacturing of autonomous driving. Among them, automakers usually become the core of integrating technologies and products of other enterprises due to their strong vehicle manufacturing capabilities. These types of enterprises are directly engaged in the R\&D or production of ICV technology, and they constitute the industrial collaborative innovation alliance within the core enterprises. Secondly, the main technology and component suppliers of ICV, including perception system suppliers (map manufacturers, sensor suppliers), communication system suppliers (communication and network service providers), decision system suppliers (chips, algorithms, software suppliers), control and execution system suppliers (system integrators, electronic component suppliers, and auto parts suppliers), etc., provide the core enterprises with technology and parts. The third is the auxiliary innovation element, mainly including universities and research institutions, science and technology service intermediaries, financial investment institutions, etc., providing auxiliary technology innovation and R\&D support. The fourth is the element of other market players, which mainly includes the government and users, among which users include corporate users and individual users. Corporate users mainly refer to the application-oriented enterprises and institutions (such as logistics enterprises, sanitation departments, port enterprises, etc.) that let the ICV land. The government provides policy support and an institutional guarantee for industrial development, and it creates a favorable market environment for it. The latter three categories constitute a collaborative innovation alliance among stakeholders in the ICV industry chain and they interact dynamically with the internal alliance among core enterprises (Figure 3).

According to the method and strategy of promoting industrial collaborative innovation and the open innovation system of the test field, two collaborative innovation paths of the ICV industry can be evolved by relying on the test field, namely, the industrial collaborative innovation path led by the core enterprises in the test field and the industrial collaborative innovation path led by the test field. 


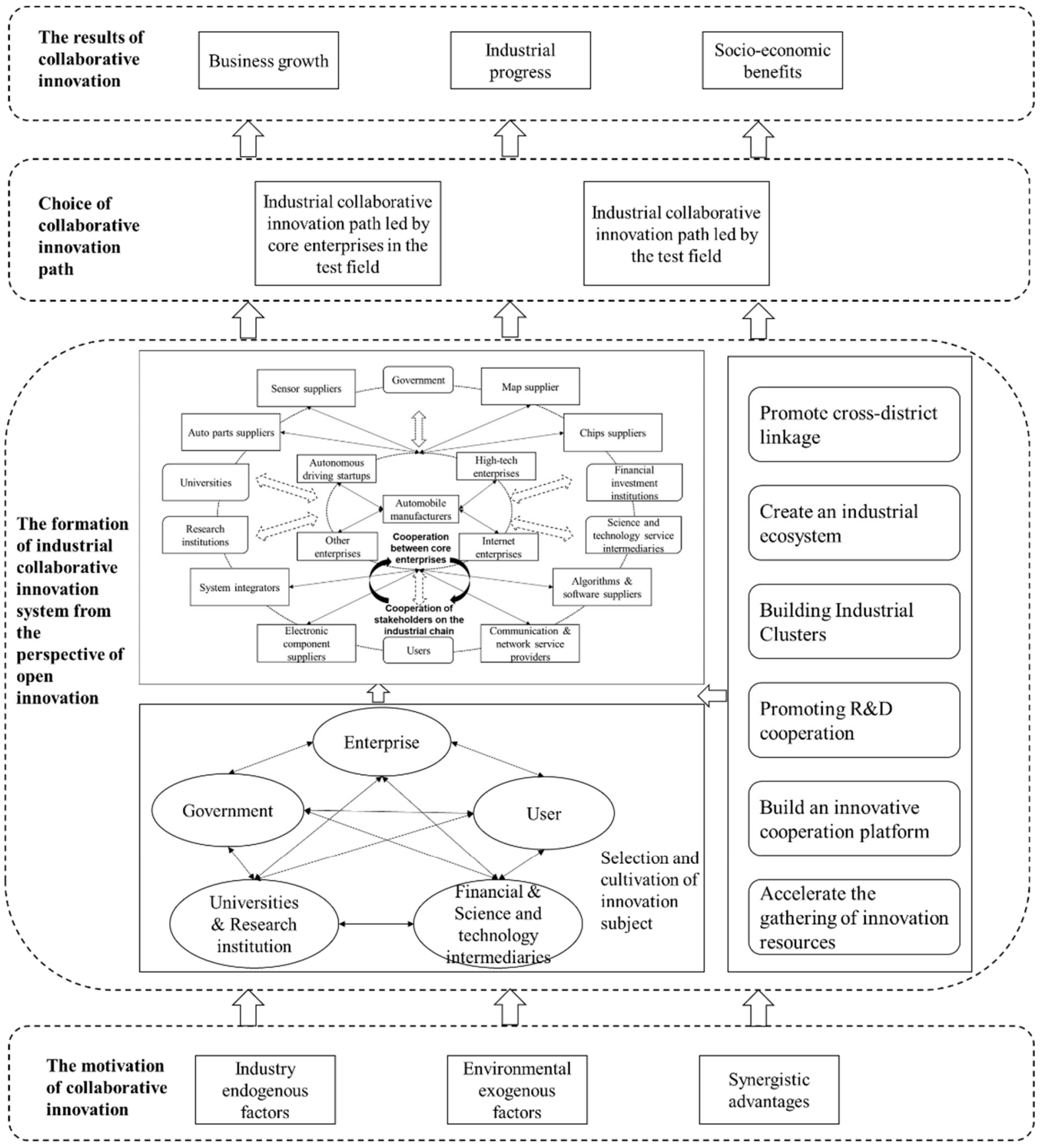

Figure 3. The collaborative innovation mechanism of ICV industry based on test fields.

\subsection{Industrial Collaborative Innovation Path Led by Core Enterprises in the Test Field}

The industrial collaborative innovation path that is led by the core enterprises of ICV in the test field emphasizes the interaction between enterprises engaged in the R\&D of ICVs and other enterprises and market players in the test field. Through the internal operation of the core enterprise, it will actively acquire external resources and communicate and integrate with the internal resources of the core enterprise, in order jointly realize the innovation of technologies and products in the ICV industry and promote the industrialization process (Figure 4). 


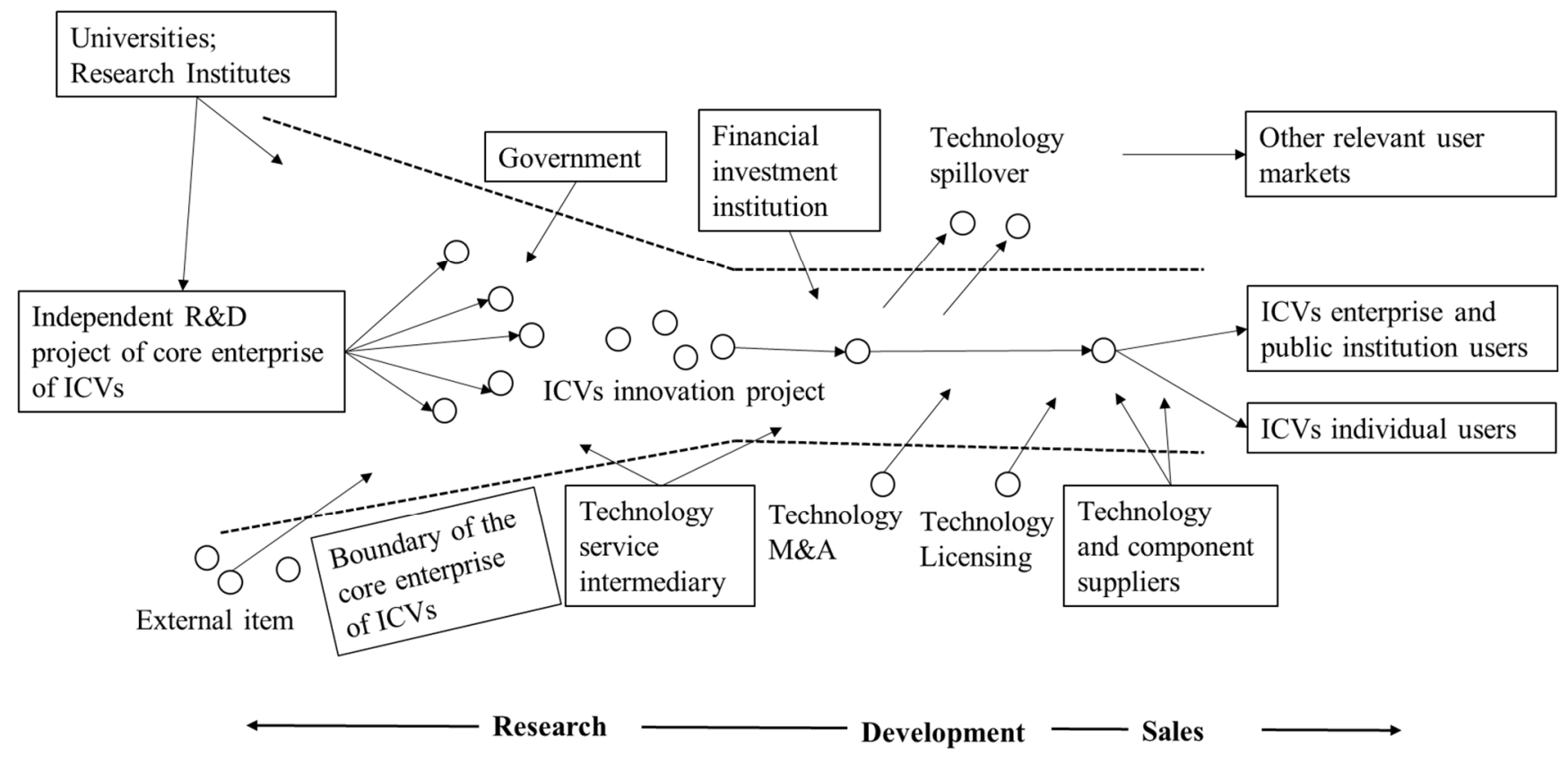

Figure 4. Collaborative innovation path of the industry led by the core enterprises of ICV in the test field.

The path relies on the gathering of innovation resources in the test field and the core enterprises' access to innovation resources. The managers of the test field attract multiple types of core enterprises of ICV, universities and research institutions, suppliers of technologies and components, financial investment institutions, technology service intermediaries, and other innovation resources to enter the test field or establish cooperative alliance relationships based on the test field and build a platform for innovation cooperation, etc., through investment attraction and the construction of supporting environment in the test field. Universities and research institutions are the main sources of innovative talents and innovative knowledge. The government provides directional guidance and financial support to create a favorable institutional environment. Financial investment institutions provide financial support in the process of R\&D and production. Technology service intermediaries have an important role in the process of the transformation of technological achievements and technology transfer.

Technology and component suppliers are not only essential in the production of ICV in the industry chain supply side, but also in the technology R\&D partners that are generally chosen by core enterprises, such as chip, sensor suppliers, communication service providers, etc. Similarly, core enterprises, such as automobile manufacturers, Internet enterprises, autonomous driving startups, and high-tech enterprises that are engaged in the R\&D and production of ICVs, are not completely competitive with each other. They have common cooperative relationships, such as the strategic cooperation between Baidu and FAW, Horizon Robotics and Neolix, Pony. ai, and Guangzhou Auto. The clustering of these subjects creates good external conditions for the core enterprises to obtain innovation resources. However, the ultimate realization of collaborative innovation depends on the core enterprises' internal ability to acquire and transform innovation resources. The stronger the ability, the higher the degree of their acquisition and utilization of external resources, especially the ability to absorb and transform heterogeneous knowledge. In the open innovation framework, the core enterprises of ICV in the test field are used as the link between knowledge inflow and outflow, and the knowledge from different external subjects, such as universities and research institutions, government, and other enterprises, are integrated to make up for their own deficiencies and realize the complementary advantages of innovation resources. Subsequently, they combine internal knowledge and resources to generate new knowledge and technologies through learning, transformation, and reuse, and finally realize the innovation of ICV products and services. 


\subsection{Industrial Collaborative Innovation Path Led by the Test Field}

The industrial collaborative innovation path that is led by the test field is to take the whole ICV test field or demonstration zone as the main body of collaborative innovation. Exchange and cooperation are realized with other test fields or demonstration zones in the region or across regions through knowledge sharing and knowledge diffusion, forming a collaborative innovation and mutual benefit between multiple test fields and demonstration zones, and jointly promoting the development of the whole industrial innovation and commercialization (Figure 5).

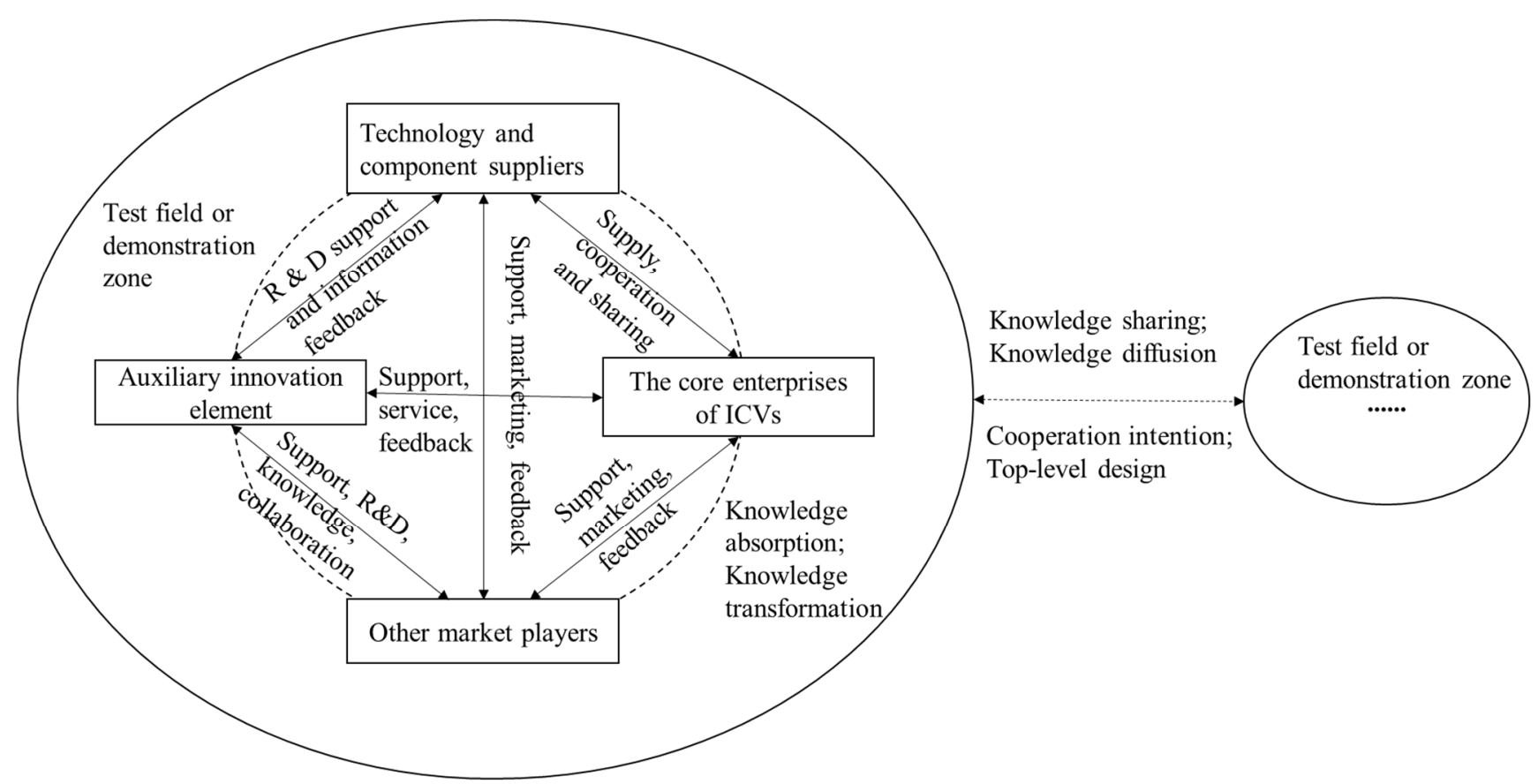

Figure 5. Industrial collaborative innovation path led by the test field.

The path is built on the basis of cooperation and innovation among the subjects in the test field, and it further takes the test field as an innovation subject. By establishing a cross-regional linkage mechanism, the collaborative innovation of the intelligent networked automobile industry is realized. On the one hand, it is the linkage among the test field in the region. Test fields and demonstration zones in the same region usually have their own positioning and planning, and, although there is some competition, they also have conditions for cooperation. For example, Beijing's Yizhuang and Haidian bases focus on the testing and verification of autonomous vehicles, Shougang Park focuses on application demonstration, and Shunyi is a traditional auto industry district in Beijing, with an auto industry base and a commitment to building an ICV town. They can establish an integrated R\&D-production-testing-demonstration-commercialization promotion system for the innovation and development of the ICV industry in the city through reasonable planning and layout, coordination, and cooperation. Subsequently, build and improve the linkage development system of the whole chain, the whole process, the integration, and the marketoriented, and promote the formation of a coordinated development pattern of ICV test field with mutual support and cooperation. On the other hand, it is the linkage between cross-regional test field, which is, the linkage of a test field between different provinces and cities. This kind of linkage is more difficult, involving cross-regional resource allocation and planning identification, and it is easier to achieve between regions that are geographically close or have common planning. For example, Hebei and Beijing, because of the advantages of Beijing-Tianjin-Hebei integration strategy, geographic proximity, and convenient flow of resources and technologies, have been jointly promoted by the Ministry of Industry and 
Information Technology, Beijing Municipal Government, and Hebei Provincial Government to build the National Intelligent Vehicle and Intelligent Transportation (Beijing-Hebei) Demonstration Zone, which is committed to becoming an industry gathering booster and a base for intelligent vehicles industry development.

The establishment of cross-region linkage mechanism depends on the communication and coordination between the government and test field management departments and the knowledge sharing and knowledge diffusion among the sites. At the early stage of industrial development, the test field may not be willing to cooperate with each other due to different planning concepts and the initial idea of "land enclosure". For example, in the interview, the person that was in charge of Shunyi BeiXiaoying mentioned that Beijing Yizhuang Base was willing to cooperate with Shunyi, but Shunyi had its own ideas regarding construction and operation, so no cooperation was reached for the time being. Therefore, the realization of cross-regional test field synergy in the early stage requires the strength of the higher government in addition to the efforts of the test field management department or inter-agency.

The local government should reasonably select the partners according to the local industrial planning and development needs. This opens up the channels of coordination and communication among the inter-regional test field from the perspective of top-level design. From here, a trust relationship is built up, and regional industrial synergy and innovation are promoted. Cross-regional knowledge sharing and knowledge diffusion built on the basis of cooperation and trust play an important role in the process of cooperative innovation that was carried out by the test field. The test field subjects that were involved in innovation cooperation have their own advantages and disadvantages in terms of technology and resources. Such differences in knowledge potentials will generate knowledge diffusion and sharing among the test field, realize the flow of knowledge among test field, and bring differentiated high-quality knowledge resources to test field. After obtaining new knowledge and resources from the outside world, the test field generates new knowledge and technology through internal innovation subjects' knowledge absorption, integration, processing, and reuse, and then promotes industrial innovation.

\section{Conclusions and Recommendations}

This paper takes the test field of ICV in Beijing as the object of case study, draws on the coding method of grounded theory, and explores the collaborative innovation of ICV industry based on the test field through the logic of "Motivation-Action-Result". From the perspective of open innovation, we optimize the collaborative innovation mechanism based on the test field as a platform and analyze the path of collaborative innovation on this basis. The study shows that: (1) the main motives for promoting the formation of test-field-based collaborative innovation in the ICV industry include industrial endogenous factors, environmental exogenous factors, and synergistic advantages. (2) The main methods for promoting test-field-based industrial collaborative innovation include: accelerating the gathering of innovation resources, building an innovation cooperation platform, promoting R\&D cooperation, building industrial clusters, creating an industrial ecosystem, and promoting cross-regional linkage. (3) The realization of collaborative innovation in the ICV industry based on the test field is important for the growth of enterprises, industrial progress and the improvement of social and economic benefits. (4) The government, enterprises, universities and research institutions, financial investment and technology intermediaries, and users are the main power sources of open innovation in the ICV test field. Through the above-mentioned collaborative innovation approach for subject cultivation and selection, a multi-subject open collaborative innovation that is based on the test field is formed. (5) Relying on the open innovation system of the ICV test field, two industrial collaborative innovation paths can be evolved: the industrial collaborative innovation path that is led by the core enterprises in the test field and the industrial collaborative innovation path led by the test field. Based on the above research, the following suggestions are made 
to promote the collaborative innovation of the ICV industry based on the test field from the perspective of the government and management department.

1. Play the guiding role of the government, accelerate the pace of policy innovation, and support the collaborative development of the industry from the perspective of a top-level design. First, accelerate the pace of revision of relevant management systems and laws and regulations, especially the standardization and improvement of the management system of self-driving road tests and the right-of-way of autonomous vehicles, business permits, and accident attribution. This is the institutional prerequisite for the large-scale market promotion of autonomous vehicles. Second, promote the establishment of a collaborative innovation platform for the ICV industry based on the test field. Promote the gathering of innovation resources in the test field through strategic planning, financial and tax incentives, as well as other innovative policies, so as to provide convenience and preferential conditions for the stakeholders of the ICV industry chain in the test field. Third, the government takes the lead in building bridges for cross-region linkage among test field. Open up channels for cross-region cooperation from the perspective of top-level design, accelerate test data sharing, the mutual recognition of test results, knowledge and resource sharing, etc., pay more attention to removing barriers to cooperation [44], and promote the establishment of trust relationships among the test field.

2. Support the establishment of industrial innovation alliances using the test field and demonstration zones as platforms. China's ICV test field gathers multiple types of innovation subjects, such as government, universities and research institutions, and enterprises, because they are usually built in conjunction with application demonstration zones. Accordingly, make full use of this condition to establish an ICV industry innovation alliance. On the one hand, it builds a platform for collaborative innovation among subjects in the test field, breaks down communication barriers, smooths communication channels, and reduces the cost of collaborative innovation. On the other hand, it promotes the construction of industrial clusters in the test field, creates a regional ICV industrial ecosystem, improves the industrial development environment, and enhances the industrial adsorption capacity of the test field and its region, thus further accelerating the gathering of innovation resources and forming a virtuous cycle.

3. Promote the diversification of innovation subjects and resources in the test field and play the role of intermediary institutions, such as finance. At present, the innovation subjects in the test field are mainly government, enterprises, universities, and research institutions, while intermediaries, such as financial investment institutions, are relatively few or lacking. Financial investment institutions are an important resource in assisting innovation, and they are particularly important in the development of innovation in the ICV industry because of the large amount of capital investment that is required for the construction and operation of the test field, the preliminary $R \& D$, and production of ICV. Take the initiative to introduce banks, venture capital, insurance, and other financial investment institutions into the test field, or join the industrial alliance that formed with the test field as a platform to provide sufficient financial support for the technological innovation and industrialization of ICV in the test field, and provide a financial flow for the collaborative innovation of all subjects.

4. Relying on the test field to accelerate the pace of technological innovation and industrialization of the results of ICV. Give full play to the technical advantages of the innovation subjects in the test field, build a R\&D cooperation platform that relies on the test field, and promote scientific research cooperation among subjects. Focus on key technologies in the fields of perception system, communication system, decisionmaking system, and control execution system. Break through the bottlenecks of ICV technologies and components, such as sensors and chips, and improve the technical innovation capacity, independent $R \& D$, and manufacturing capacity of enterprises that are related to ICV in China. At the same time, supporting the construction of 
the whole industry chain, integration construction, and the construction of the cooperation system between government, industry, academia, research, and application to create an ICV ecosystem. Finally, providing the necessary guarantee for the transformation of the technological achievements of ICV, and providing the testing and application scenarios for demonstration operations nearby in order to accelerate the pace of industrialization and commercialization.

\begin{abstract}
Author Contributions: Conceptualization, F.Z. and Y.L.; methodology, F.Z.; validation, R.C.; formal analysis, F.Z. and Y.L.; investigation, F.Z. and R.C.; resources, R.C. and Y.L.; data curation, F.Z.; writing-original draft preparation, F.Z.; writing-review and editing, Y.L. and R.C.; visualization, F.Z. and Y.L.; supervision, Y.L. and R.C. All authors have read and agreed to the published version of the manuscript.

Funding: This research was funded by the Fundamental Research Funds for the Central Universities, Research on Collaborative Innovation of Smart Networked Vehicle Industry from the Perspective of Knowledge Diffusion, grant number (2021YJS051); Capital High-end Think Tank Project, “Research on Road Traffic Regulations and Relevant Operation Supervision Policies Adapted to Autonomous Driving", grant number (2020ZKKT005); Beijing Philosophy and Social Science Project, "Research on the Green Development of Electric Vehicles in Beijing-Tianjin-Hebei Region under the Open Platform", grant number (19GLB030).
\end{abstract}

Data Availability Statement: Not applicable.

Acknowledgments: The authors would like to thank the anonymous reviewers for their reviews and comments.

Conflicts of Interest: The authors declare no conflict of interest.

\title{
References
}

1. Wei, Y.; Huixiong, X. Huawei Enters the Game to Build the Main Engine of Automotive Intelligence; Essence Securities: Shenzhen, China, 2020.

2. Chuxiong, F.; Kai, W. Autonomous Driving is Approaching, and the In-Vehicle Sensor Market is Welcoming Rapid Development; China Galaxy Securities Research Institute: Beijing, China, 2021.

3. China Intelligent Networked Vehicle Industry Innovation Alliance Group. Report on China's Smart Internet-Connected Passenger Vehicle Sales; China Intelligent Networked Vehicle Industry Innovation Alliance: Beijing, China, 2020.

4. $\quad$ Bing, Z.; Peixing, Z.; Jian, Z.; Hong, C.; Zhigang, X.; Xiangmo, Z.; Weiwen, D. Research progress of scenario-based virtual testing of self-driving vehicles. Chin. J. Highw. 2019, 32, 1-19.

5. Lai, J.K. Patent posture analysis of intelligent decision-making technologies for Intelligent Connected Vehicless. Chin. Invent. Pat. 2018, 15, 114-118.

6. Chunlin, F. Development dilemmas and coping strategies of China's Intelligent Connected Vehicles industry. Contemp. Econ. Manag. 2018, 40, 64-70.

7. Chesbrough, H. Open platform innovation: Creating value from internal and external innovation. Intel Technol. J. 2003, 7, 5-9.

8. Lichtenthaler, U. Open Innovation: Past Research, Current Debates, and Future Directions. Acad. Manag. Perspect. 2011, 25, 75-93.

9. Lyu, Y.; Zhu, Y.; Han, S.; He, B.; Bao, L. Open innovation and innovation Radicalness-the moderating effect of network embeddedness. Technol. Soc. 2020, 62, 101292. [CrossRef]

10. Liangmou, G.; Wenjia, M. Open innovation: Connotation, framework and Chinese context. Manag. World 2014, 157-169. [CrossRef]

11. Pustovrh, A.; Rangus, K.; Drnovek, M. The role of open innovation in developing an entrepreneurial support ecosystem. Technol. Forecast. Soc. Chang. 2020, 152, 119892. [CrossRef]

12. Zhaoru, L. A Study on the Impact of Open Innovation and Dynamic Capabilities on the Growth of Cross-Border Firms. Master's Thesis, Huaqiao University, Xiamen, China, 2019.

13. Yingying, F.; Jianjiao, L. Creating an ecosystem for China's chip industry from open collaborative innovation. Ind. Econ. Rev. 2018, 9, 104-115.

14. Wang, W.-H.; Zhang, Z.; Cai, R.-L. A study on the synergy effect of collaboration management among open innovation organizations affecting knowledge. Res. Dev. Manag. 2018, 30, 38-48.

15. Ziguang, R.; Pengbin, G. A study on the relationship between two-way open innovation and its synergy, business model and firm innovation performance. Manag. Rev. 2020, 32, 116-130.

16. Zeyang, L. Research on the Mechanism and Path of Inter-Firm Collaboration in Open Innovation. Master's Thesis, Hebei University of Technology, Tianjin, China, 2017. 
17. Yanting, G.; Gang, Z.; Zhongwen, Q. A preliminary investigation on the new catch-up path and model of enterprises based on cross-border collaboration under the perspective of open innovation. Sci. Res. Manag. 2019, 40, 169-183.

18. Laursen, K.; Salter, A. Open for innovation: The role of openness in explaining innovation performance among U.K. manufacturing firms. Strateg. Manag. J. 2006, 27, 131-150. [CrossRef]

19. Knudsen, M.P.; Mortensen, T.B. Some immediate-But negative-Effects of openness on product development performance. Technovation 2011, 31, 54-64. [CrossRef]

20. Graciela, C.D.; Jones, J.; Statsenko, L. Managing Innovation Networks for Knowledge Mobility and Appropriability: A Complexity Perspective. Entrep. Res. J. 2016, 6, 75-109.

21. Lei, S. Research on the Mechanism of Enterprise Innovation Dynamics in Open Innovation Environment. Master's Thesis, University of Science and Technology of China, Hefei, China, 2019.

22. Chen-Ning, J.; Hong, Z. Open innovation in Chinese firms: Institutional environment, "competition" relationship and innovation performance. Manag. World 2020, 36, 139-160.

23. Yu-Fen, C.; Jin, C. A study on the mechanism of open innovation for innovation performance. Res. Manag. 2009, $30,1-9,28$.

24. Yuanyuan, Y. Research on the Operation Mechanism of Open Innovation Ecosystem Based on Research Consortium. Master's Thesis, Jinan University, Jinan China, 2019.

25. Xie, X.; Wang, H. How can open innovation ecosystem modes push product innovation forward? An fsQCA analysis. J. Bus. Res. 2020, 108, 29-41. [CrossRef]

26. Zhuo-Ping, Y.; Xing-Yu, X.; Jun-Yi, C. Advances in testing technologies and applications of self-driving vehicles. J. Tongji Univ. 2019, 47, 540-547.

27. Hong, S.; Kang, Y.; Hailin, X.; Qin, X.; Shan, H. Research on the construction of basic test scenarios for self-driving vehicles. Chin. J. Highw. 2019, 32, 245-254.

28. Shijia, Z.; Nan, X.; Quansi, C. Characteristics and insights of California's Autonomous Vehicles road test management. Sci. Technol. Manag. Res. 2020, 40, 220-225.

29. Huang, L. Research on Field Testing and Evaluation of Partially Self-Driving Vehicles. Master's Thesis, Chongqing University, Chongqing, China, 2018.

30. Jun, L. How Institutional Innovation Confronts Automated Driving-Observations and Reflections Based on the Road Testing System. China Sci. Technol. Forum 2019, 44-51. [CrossRef]

31. Jixia, W.; Daqing, F. Legal regulation of road testing of Autonomous Vehicles. Adm. Reform 2019, 37-43. [CrossRef]

32. Lee, D.; Hess, D.J. Regulations for on-road testing of connected and automated vehicles: Assessing the potential for global safety harmonization. Transp. Res. Part A Policy Pract. 2020, 136, 85-98. [CrossRef]

33. Di, Y. Research on Administrative Regulations for Road Testing of Self-Driving Vehicles. Master's Thesis, Southeast University, Nanjing, China, 2019.

34. Ting, Z. Research on the Administrative License of Intelligent Connected Vehicles Road Testing. Master's Thesis, People's Public Security University of China, Beijing, China, 2020.

35. Xiaoshuai, Z. Development of a Virtual Test Platform for Autonomous Driving Based on Human-Vehicle-Environment Modeling. Master's Thesis, Chongqing University of Technology, Chongqing, China, 2019.

36. Rongjie, Y.; Ye, T.; Jian, S. Virtual testing of high-grade autonomous vehicles: Research progress and frontiers. Chin. J. Highw. 2020, 33, 125-138.

37. Liu, P.; Xu, Z.; Zhao, X. Road tests of self-driving vehicles: Affective and cognitive pathways in acceptance formation. Transp. Res. Part A Policy Pract. 2019, 124, 354-369. [CrossRef]

38. Zejin, G. Observation and Research on Baidu Apollo Intelligent Driving Open Platform from the Perspective of Innovation Diffusion. China Sci. Technol. Forum. 2020, 147-152. [CrossRef]

39. Yin, R.; Thousand, S. Case Study Research: Design and Methods, 4th ed.; Blackwell Science Ltd.: Hoboken, NJ, USA, 2009.

40. Eisenhardt, K.M. Building theories from case study research. Acad. Manag. Rev. 1989, 14, 532-550. [CrossRef]

41. Zongyuan, L.; Wenping, L. A study on the dynamic cooperation evolution between platform enterprises and partners based on social capital theory-a longitudinal case study of Cainiao Network. Bus. Econ. Manag. 2020, 15-27. [CrossRef]

42. Tao, M.; Yuqiao, G.; Zheng, D.; Wei, W. Research on the mechanism of user value ingenuity in sharing economy platforms-A case study of Airbnb and Idlefish. Sci. Technol. Manag. 2020, 41, 111-130.

43. Yue, L.; Hang, G.; Hongqi, W.; Zhuo, W. The incentive elements and role mechanism of alliance collaborative innovation based on rooting theory. China Sci. Technol. Forum 2020, 129-137. [CrossRef]

44. Robaczewska, J.; Vanhaverbeke, W.; Lorenz, A. Applying open innovation strategies in the context of a regional innovation ecosystem: The case of Janssen Pharmaceuticals—ScienceDirect. Glob. Transit. 2019, 1, 120-131. [CrossRef] 